\title{
ANALYSIS ON THE CHANGE OF VEGETATION COVERAGE IN QINGHAI PROVINCE FROM 2000 TO 2012
}

\author{
Jiao.Wang ${ }^{\text {a,b }}$, Qin.Yan ${ }^{\text {a }}$, Zhengjun.Liu ${ }^{\text {a }}$, Chengfeng. Luo ${ }^{\text {a }}$
}

\begin{abstract}
${ }^{a}$ Chinese Academy of Surveying and Mapping, Institute of Photogrammetry and Remote Sensing, No.28 Lianhuachi Xi Road, Haidian District, Beijing, P.R.China - 772072971@qq.com, (yanqin, zjliu,cfluo)@ casm.ac.cn

${ }^{\mathrm{b}}$ Shandong University of Science and Technology, College of Geomatics, No.579 Qianwangang Road, Huangdao District, Qingdao, Shandong, P.R.China - 772072971@qq.com
\end{abstract}

KEY WORDS: Vegetation Coverage, Qinghai Province, Coefficient of Variability, Trend Line Analysis, Change Analysis, MODIS

\begin{abstract}
:
Qinghai Province is one of the important provinces on the Qinghai-Tibet Plateau in China. Its unique alpine meadow ecosystem makes it become the most concentrated areas of biodiversity in high altitudes in the world. Researching the vegetation coverage and changes of Qinghai province can reflect effectively and timely processing of changes and problems of ecological quality in the region. This research will give a long time series monitoring of the vegetation coverage of Qinghai province based on maximum value composite (MVC) and S-G filtering algorithm using MODIS data of the year of 2000-2012, then analyze the change using coefficient of variability $(\mathrm{CV})$ and trend line analysis. According to research, during the past 13 years, more than half of Qinghai Province's vegetation coverage is well, both the east and south have a high coverage, while the northwest is lower. The changing of vegetation coverage also has showed a steady and improving trend in 13 years. The largest area is slight improved area is about $29.08 \%$ of the total area, and the second largest area is significant improved area is about $21.09 \%$ of the total area. In this research can learn directly the vegetation coverage and changes of Qinghai province and provide reference and scientific basis for the protection and governance of ecological environment.
\end{abstract}

\section{INTRODUCTION}

The vegetation coverage refers to the percentage of the vegetation's vertical projection area in unite area, including the stem, leave and branch ${ }^{[1-2]}$. The vegetation coverage, a comprehensive quantitative indicator of the vegetation covering condition, is an important parameter that describes vegetation communities and ecosystem. Vegetation coverage and its change are the important indicator of regional ecosystem changing which means important to hydrology, ecology and global changes. According to the monitoring method, there are two measuring vegetation coverage methods-ground survey and remote sensing measurement ${ }^{[3]}$. The former method includes estimation method, sampling point method, quadrat sampling method, the sample strip method, etc ${ }^{[4-6]}$. But these methods have strong subjective tends, large workload and high cost which are not suitable for measuring large area coverage. With the development of remote measuring technology, it is possible to measure coverage with it. This kind of method not only saves the extra time and money that caused by traditional ground measurement, but also can simultaneously observe, eliminating the ground measurement's disadvantage of smallscale measurement.

Qinghai province, one of the four largest provinces in China, having broad land and grassland, extending 8 degree of latitude, is one of the national five major pastoral areas. Its grassland area accounts for $50.46 \%$ of the total area, mainly in QinghaiTibet Plateau, mountain Qilian and the Qidamu Basin's southwest mountains. The farmland area of the province only accounts for $1.54 \%$ of the total area, mainly distributed in the area of east Hehuang, Gonghe Basin and Chaidamu Basin. Forest land only accounts for $6.1 \%$ and mainly distributed in southeast. Researching Qinghai province's vegetation coverage with remote measuring technology can monitor its vegetation changes comprehensively, which is of great importance to the regional development and ecological construction.

With the MODIS data of NDVI and LAI of 2000-2012, this study estimates the vegetation coverage with non-density model, monitors and analyzes a long-term series of data of Qinghai province vegetation coverage in different periods, reveals its changing rules, providing evidence for scientific and rational protection and land resources utilization.

\section{DATA AND METHODS}

\subsection{Study area}

Qinghai province is located in the west of China and northeast of Qinghai-Tibet Plateau, adjacent to Xinjiang, Sichuan, Gansu, Xizang provinces. It is in east longitude $89^{\circ} 35^{\prime}-103^{\circ} 04^{\prime}$, north latitude $31^{\circ} 39^{\prime} \sim 39^{\circ} 19^{\prime}$. The whole province's length is $1200 \mathrm{~km}$, width is $800 \mathrm{~km}$. Qinghai province is an important part of the world roof. Except some areas, such as Yellow River Valley and Qidamu Basin, the rest are at an altitude of about 3000-5000 meters. In Qinghai province, the western part is higher than eastern and northwest is higher than the middle part. The terrain is so complicated that forms the unique plateau continental climate-less raining, large temperature changes and a lot of sunshine. The source of Yangtze River and Yellow River is in Qinghai, so does the Qinghai Lake, the largest inland saltwater lake. It is its unique natural environment that decides the corresponding features of its vegetation type. Its unique alpine meadow ecosystem makes it become the most concentrated areas of biodiversity in high altitudes in the world. Researching the vegetation coverage and changes of Qinghai province can reflect effectively and timely processing of changes and problems of ecological quality in the region and provide scientific evidence for vegetation protection and ecological researches. 


\subsection{Data}

\subsubsection{MODIS Data}

The remote measuring data this paper adopted is MODIS, which is one of the major sensor set on Terra and Aqua satellites that work together to observe respectively the whole surface of the Earth every 1-2 days to attain the observation data of 36 bands which will help us to understand profoundly the dynamic changes in land, ocean and the lower atmosphere. Therefore, MODIS plays an important role in the development of effective, global and forecasting interaction model; its accurate prediction will be benefit to the major decision related to environment protection.

The data we get are vegetation index product MOD13Q1, leaf area index product MOD15A2 and land coverage product MCD12Q1 of H24V05、H25V05、H26V05. The time is from May to October every year of 2000 to 2012, and the resolution are 250 meters and 1000 meters respectively.

\subsubsection{Data preprocessing}

Data pre-processing is divided into three steps. Firstly, with the MRT software provided freely by NASA, we piece up, resample and deliver projection of the downloaded data, transforming the HDF format into Tiff format and the sinusoidal map projection into Geographical longitude-latitude projection so as to get NDVI, LAI and land covering product image. Then we use the maximal value composite method to eliminate clouds and noise. The MVC, the largest selection of pixel values from multiple phase data, can eliminate the influence of clouds, atmosphere and solar altitude angle as much as possible ${ }^{[7]}$. At last, deal with the long-term series of 13 years data S-G filtering ${ }^{[8]}$ to achieve the purpose of smoothing and noise reduction.

\subsection{Research method}

\subsubsection{Vegetation coverage estimation}

Vegetation coverage inversion method mainly includes empirical model method, vegetation index method, pixel immixing model method ${ }^{[9]}$, etc. According to the remote measuring data we have, we choose density method and nondensity method ${ }^{[10-12]}$ which belong to two sub-pixel model method to calculate the vegetation coverage. The formula is as follows:

\section{(1) Density model}

Assumes that the vegetation type in pixel is single and the vertical vegetation density is high enough, that is $\mathrm{LAI} \rightarrow \infty$, $\mathrm{NDVI}_{v e g} \rightarrow \mathrm{NDVI}_{\infty}$. And then we get the vegetation coverage

$$
\mathrm{FC}=\left(\mathrm{NDVI}-\mathrm{NDVI}_{\text {soil }}\right) /\left(\mathrm{NDVI}_{\infty}-\mathrm{NDVI}_{\text {soil }}\right)
$$

(2) Non-density model

This model is similar to the former one - the assumption of the vegetation type is same, but the vertical vegetation density is smaller, that is $\mathrm{LAI}<<\infty$ and the vegetation coverage is:

$$
\begin{aligned}
& \mathrm{FC}=\left(\mathrm{NDVI}-\mathrm{NDVI}_{\text {soil }}\right) /\left(\mathrm{NDVI}_{\text {veg }}-\mathrm{NDVI}_{\text {soil }}\right) \\
& \mathrm{NDVI}_{\text {veg }}=\mathrm{NDVI}_{\infty}-\left(\mathrm{NDVI}_{\infty}-\mathrm{NDVI}_{\text {soil }}\right) \exp (-k \mathrm{LAI})
\end{aligned}
$$

In formula(1)(2)(3), FC is vegetation coverage, NDVI is high vertical density. $\mathrm{NDVI}_{\text {veg }}$ is pixel's NDVI value that covered totally by green vegetation. $\mathrm{NDVI}_{\text {soil }}$ is pixel's NDVI value that covered by soil. LAI is the leaf area index, $k$ is extinction coefficient, and here we take the constant $1^{[13-15]}$.

The key of calculation of FC is to determinate the parameters of $\mathrm{NDVI}_{\text {veg }}$ and $\mathrm{NDVI}_{\text {soil }}$. In order to eliminate the influence of noise data, we gather up the vegetation index probability distribution of varied soil, set the confidence level as $0.2 \%$. In this confidence interval, the maximum and minimum values are exactly the parameters of $\mathrm{NDVI}_{v e g}$ and $\mathrm{NDVI}_{\text {soil }}$.

The estimation model applied by various soil types and the corresponding soil coverage types are shown in Table1.

\begin{tabular}{|c|c|c|}
\hline $\begin{array}{c}\text { Land } \\
\text { cover } \\
\text { types }\end{array}$ & $\begin{array}{c}\text { Land cover types } \\
\text { corresponding to MCD12Q1 }\end{array}$ & $\begin{array}{c}\text { Estimation } \\
\text { model }\end{array}$ \\
\hline Meadow & $\begin{array}{c}\text { Woody tropical savannas, } \\
\text { tropical savannas, grasslands, } \\
\text { wetlands permanently }\end{array}$ & $\begin{array}{c}\text { Non-density } \\
\text { model }\end{array}$ \\
\hline Thickets & Dense bush, sparse bushes & $\begin{array}{c}\text { Density } \\
\text { model }\end{array}$ \\
\hline Woodland & $\begin{array}{c}\text { Evergreen broadleaf forest, } \\
\text { evergreen coniferous forest, } \\
\text { deciduous forest, deciduous } \\
\text { forest, mixed forest }\end{array}$ & $\begin{array}{c}\text { Density } \\
\text { model }\end{array}$ \\
\hline $\begin{array}{c}\text { Farm \& } \\
\text { Town }\end{array}$ & $\begin{array}{c}\text { Farmland, farmland } \\
\text { vegetation staggered, towns } \\
\text { and buildings }\end{array}$ & $\begin{array}{c}\text { Non-density } \\
\text { model }\end{array}$ \\
\hline $\begin{array}{c}\text { Sparse } \\
\text { vegetation }\end{array}$ & Barren or sparse vegetation & $\begin{array}{c}\text { Non-density } \\
\text { model }\end{array}$ \\
\hline $\begin{array}{c}\text { Water } \\
\text { body }\end{array}$ & Water, snow and ice & $\begin{array}{c}\text { Not involved } \\
\text { in the } \\
\text { calculation }\end{array}$ \\
\hline
\end{tabular}

Table 1. Different land cover types and the vegetation coverage estimation model

2.3.2 Analysis of changing of vegetation coverage

Changes in coverage and variation of vegetation are one of the key problems in the judges of the vegetation's health condition in certain time. This is because the constant changes have the biggest influence on production practice. We can get the change of vegetation coverage through the application of the following methods.

\subsubsection{Time series analysis of vegetation coverage stability}

In order to grasp the vegetation coverage's space pattern and distribution of Qinghai province, calculate the annual maximum CV of 2000-2012, carries on statical analysis and estimates the vegetation coverage's stability in time series.

$$
\mathrm{CV}=\frac{\sigma}{\overline{\mathrm{x}}}
$$

In the formula (4), $\mathrm{CV}$ is the coefficient of variability, $\sigma$ is standard deviation, $\bar{x}$ is mean value. The larger the parameter of $\mathrm{CV}$ of each pixel, the more separated the distribution of data, the smaller the fluctuation of annual maximum vegetation coverage in time series, the more violent the change. Otherwise, the data distribution is centered, annual maximum vegetation coverage fluctuation small, the vegetation coverage is stable. 


\subsubsection{Change Trend Line Analysis ${ }^{[16]}$}

The degree of change for vegetation coverage can be analyzed with change tendency line, which can be expressed with minimum power of the linear regression equation slope of the vegetation coverage within a period of time as following:

$$
\theta_{\text {slope }}=\frac{n \times \sum_{i=1}^{n} i \times M_{f c, i}-\sum_{i=1}^{n} i \sum_{i=1}^{n} M_{f c, i}}{n \times \sum_{i=1}^{n} i^{2}-\left(\sum_{i=1}^{n} i\right)^{2}}
$$

Here $i$ is number of the year in the corresponding period of time. $\mathrm{M}_{\mathrm{fc}, \mathrm{i}}$ is the vegetation coverage value in the $i$ year. The tendency line of the pixel is a simulated general change of the vegetation coverage for the object pixel in a long time. But the line is not simple connection between the last year and the first year. Here the positive or negative result value indicates that the vegetation coverage improved or degraded, $\theta_{\text {slope }}>0$ indicates that the vegetation coverage is improving, and $\theta_{\text {slope }}<0$ indicates that the vegetation coverage is degrading, and the absolute value of $\theta_{\text {slope }}$ embodies the degree of change.

\subsection{Result of the vegetation coverage}

We calculate the vegetation coverage from May to October each year from 2000 to 2012 by the method of calculating vegetation coverage above using ENVI/IDL, and compute the maximum vegetation coverage and the average of annual vegetation coverage by using this result. To verify the accuracy of estimated vegetation coverage with the 59 field measured points in August 2011, the accuracy is $87.13 \%$ calculated by the root mean square error. Average of annual maximum vegetation coverage can reflect the average condition of vegetation biomass. During the period from 2000 to 2012, the spatial distribution of vegetation coverage in Qinghai province can be seen as figure 1 . We can see that the vegetation coverage in Qinghai province from 2000 to 2012 is overall presentation of the status of high in southeast and low in northwest. This situation is due to the south of Qinghai province is often rain and snow, many lakes and marshes are there, and it is also the birthplace of the Yangtze River, Yellow River and the Lancang River, its warm climate and irrigation facilities are suitable for the growth of vegetation. And the northeast of Qinghai province have developed trellis drainage, this area is an excellent pasture, grass is growth in most of this area except for a few top of mountains perennial snow, the climate of valley sides is warm and moist, the soil is fertile, so this area is also a major grainproducing areas in Qinghai province. The southwest of Qinghai province is China's third largest inland basin - the Qaidam Basin, it is the deepest place in Qinghai-Tibet Plateau, in the basin Gobi and desert are widely distributed, so it is unsuitable for the growth of vegetation, and vegetation coverage is low. In order to give an intuitive and convenient map, we referred the professional standard, "The main technical regulations for national desertification monitoring" [17], and divided the vegetation coverage into 5 types. The figure 2 and Table 2 show the distribution of different levels and area ratio clearly.

According to figure 2 and table 2, during the period from 2000 to 2012, average of annual maximum vegetation coverage of in northwest of Qinghai province is below 0.3, belonging to the low coverage area; average of annual maximum value in mid area between 0.3 and 0.55 , belonging to the medium coverage area; average of annual maximum value in eastern and Southern part is above 0.75 , belonging to the very high coverage area.

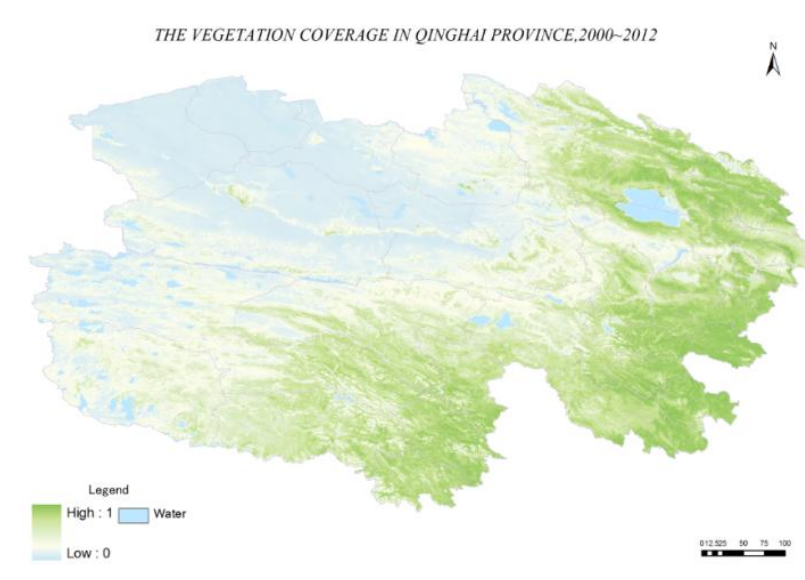

Figure 1. The average of annual maximum vegetation coverage during the period from 2000 to 2012 in Qinghai province

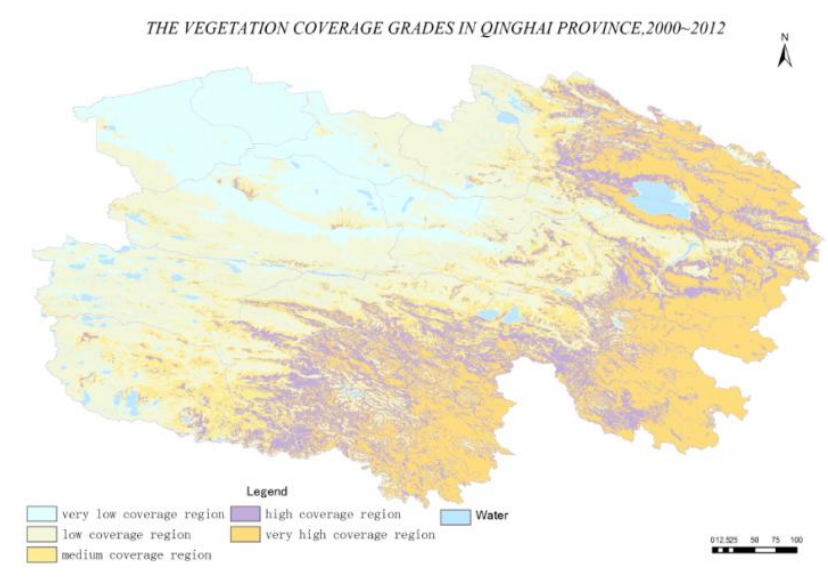

Figure 2 . The average of annual maximum vegetation coverage during the period from 2000 to 2012 in Qinghai province (using different levels)

\begin{tabular}{|c|c|c|c|c|}
\hline \multirow{2}{*}{ Level } & \multirow{2}{*}{$\begin{array}{c}\text { Coverage } \\
\text { Fraction }\end{array}$} & Types & \multicolumn{2}{|c|}{$\begin{array}{c}\text { Area Ratio } \\
(\%)\end{array}$} \\
\cline { 4 - 6 } & & $\begin{array}{c}2000 \sim \\
2012\end{array}$ & 2012 \\
\hline I & $<10 \%$ & $\begin{array}{c}\text { very low } \\
\text { coverage region }\end{array}$ & 17.29 & 15.63 \\
\hline II & $10 \% \sim 35 \%$ & $\begin{array}{c}\text { low coverage } \\
\text { region }\end{array}$ & 33.50 & 32.10 \\
\hline III & $35 \% \sim 55 \%$ & $\begin{array}{c}\text { medium } \\
\text { coverage region }\end{array}$ & 14.77 & 14.98 \\
\hline IV & $55 \% \sim 75 \%$ & $\begin{array}{c}\text { high coverage } \\
\text { region }\end{array}$ & 14.57 & 14.65 \\
\hline V & $>75 \%$ & $\begin{array}{c}\text { very high } \\
\text { coverage region }\end{array}$ & 19.86 & 22.63 \\
\hline
\end{tabular}

Table 2. The grade standard of vegetation coverage in Qinghai province

The spatial distribution of vegetation coverage in Qinghai province of 2012 can be seen as figure 3, and the results of vegetation coverage in different levels is shown in Figure 4. From this two figures we can see that the vegetation coverage in Qinghai province in 2012 was in good condition, except the northwest area where the vegetation coverage was very low because of the natural landscape of this area is almost arid desert, most other parts had a higher vegetation coverage. The 
distribution of different levels and area ratio are also shown in Table 2. By contrast we found that the percent of very high coverage region is about $3 \%$ higher than the average level in nearly 13 years, and the difference is larger than other types, while the medium coverage region and the high coverage region are basically same as the vegetation coverage in this levels in 13 years, which shows that the vegetation condition in Qinghai province has been becoming better during the last 13 years.

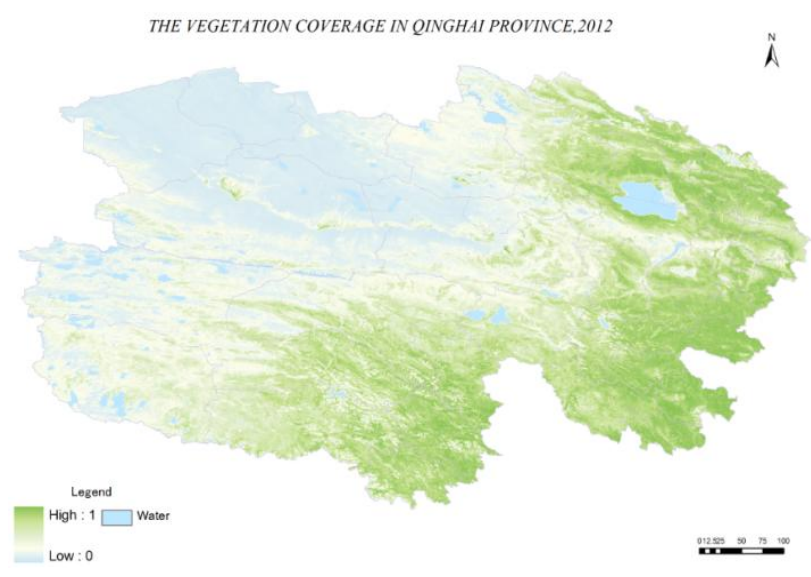

Figure 3. The average of annual maximum vegetation coverage fraction in 2012 in Qinghai province

THE VEGETATION COVERAGE GRADES IN QINGHAI PROVINCE, 2012

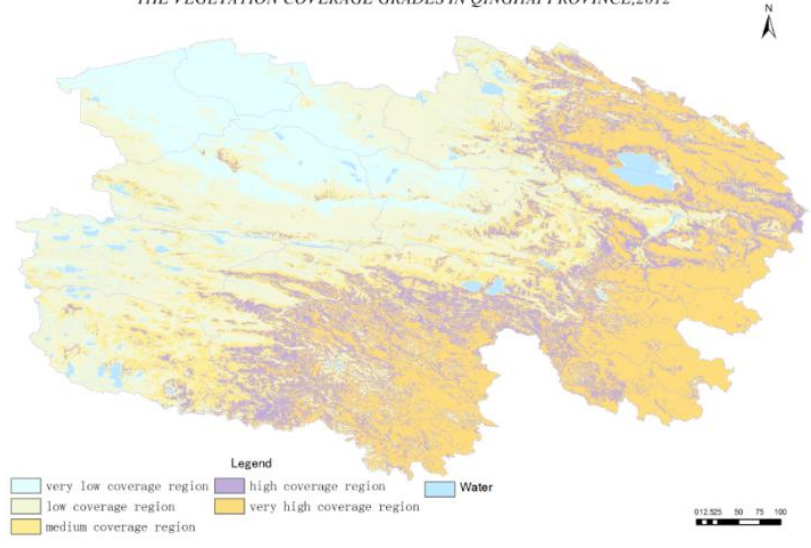

Figure 4. The average of annual maximum vegetation coverage fraction in 2012 in Qinghai province (using different levels)

\subsection{Result of change analysis}

\subsubsection{Interannual variation analysis}

During the period from 2000 to 2012, the change of average of annual maximum vegetation coverage in Qinghai province is showed as figure 5 and figure 6 . The vegetation coverage had been changing fluctuantly and presented general amelioration in the last 13 years. From the curve, the year 2001, 2005, 2009 and 2010 appears peaks, the year 2003, 2006, 2008 and 2011 trough; the largest maximum vegetation coverage presented in 2010, while vegetation coverage is lowest in 2000 .

Figure 6 also shows that during the period from 2008 to 2009, the vegetation coverage had the biggest change and the change is a good direction change, and during the period from 2010 to 2011, the vegetation coverage had the greatest extent of deteriorate.

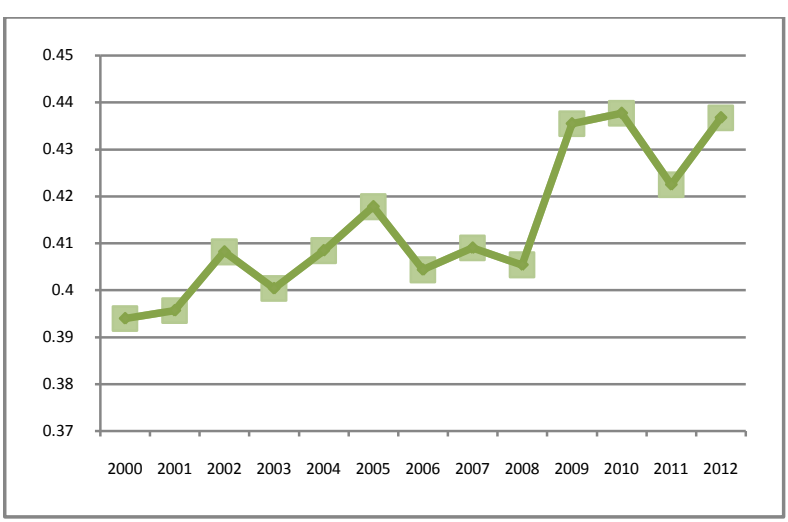

Figure 4 . The change of average of annual maximum vegetation coverage during the period from 2000 to 2012 in Qinghai province

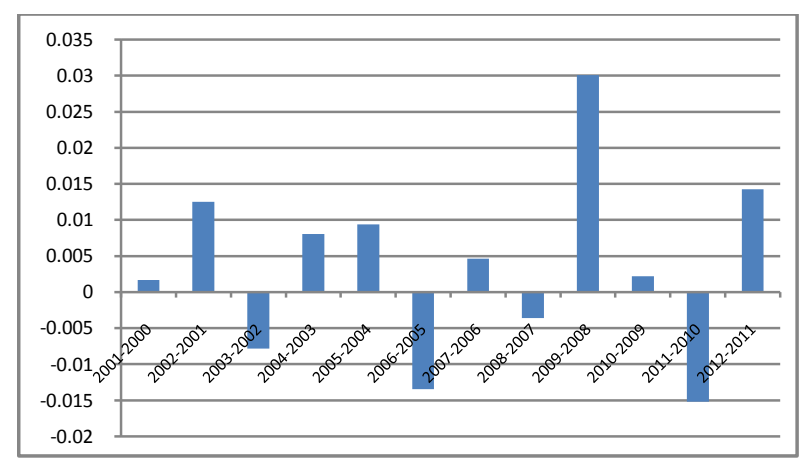

Figure 5. The change of average difference of annual maximum vegetation coverage during the period from 2000 to 2012 in Qinghai province

\subsubsection{Analysis of variation within the year}

Figure 6 shows the comparison of average of month maximum vegetation coverage in growing season during the period from 2000 to 2012 in Qinghai province. As a whole there also has an improving vegetation condition in recent 13 years. The crest and trough characteristics of curve for the month maximum vegetation coverage are consistent with that of the annual maximum vegetation coverage curve. There is highest vegetation coverage and relatively small change amplitude in August and July, while lowest vegetation coverage and relatively large change amplitude in May and October.

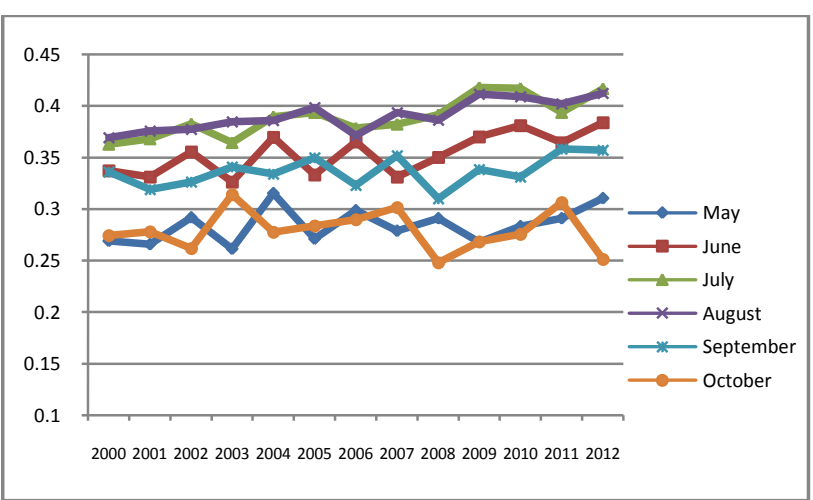

Figure 6. The comparison of average of month maximum vegetation coverage in growing season during the period from 2000 to 2012 in Qinghai province 


\subsubsection{Result of stability analysis}

The stability of vegetation coverage reflects its fluctuation degree of changes in Qinghai Province during 13 years, fluctuations in the size of index calculated by the CV 13 years Qinghai variability situation shown in Figure 7. We divide the coefficient of variation into five levels, express the variability of vegetation cover in Qinghai Province from weak to strong. As can see from Figure 7, in most parts of Qinghai Province during 13 years, the maximum annual vegetation cover relatively stable, but the coefficient of variation is larger in central and north-central regions, it is indicated that the maximum vegetation coverage change is very unstable, have extremely volatile and dramatic changes in this region during 13 years, so this area is a place which can reflect changes in vegetation sensitively, the drivers of change for this area is very important to global change response research. However, the direction of change in this area is unclear and scope, we still need to take advantage of the trend line analysis methods to analyze them to determine the direction of change.

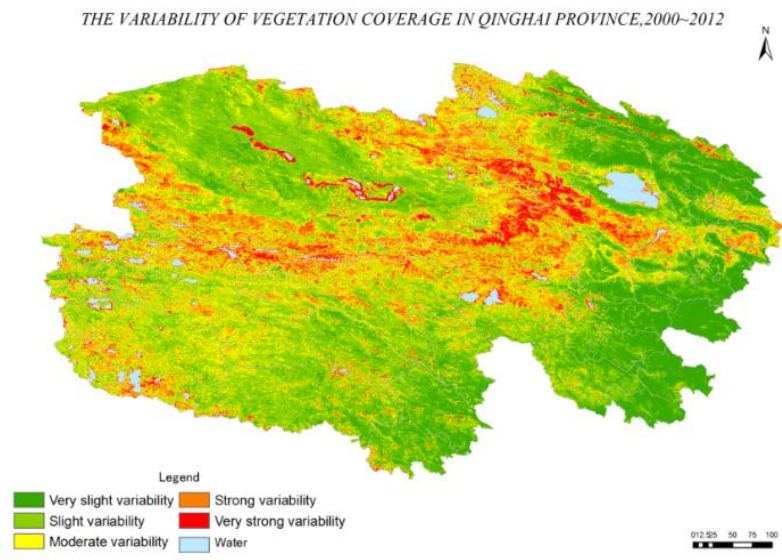

Figure 7 . The variability of vegetation coverage during the period from 2000 to 2012 in Qinghai province

\subsubsection{Result of change trend line analysis}

According to the trend line analysis formulas, combined with the results of the stability analysis, we calculated the change trends of vegetation coverage in Qinghai province from 2000 to 2012 shown in Figure 8. By the change trend line analysis, we can see that the area our study mentioned above which was extremely volatile and dramatic changes - the central and northcentral regions - are mostly positive fluctuations, ie the vegetation coverage tended to improve in this region during 13 years. Looking at the trend graph, we can see that the vegetation coverage overall improving during 13 years in Qinghai province, Only a few regions such as the West Taijnar Lake, East Taijnar Lake and other lakes surrounding the northwest of Qinghai province and parts of east of Qinghai province have a serious degradation. The statistical results of change analysis is shown in Table 3, we can see that from an overall point of view, during the period from 2000 to 2012 the vegetation coverage improvement area of Qinghai province accounts for $81.67 \%$ of the total area, degradation area occupies $18.33 \%$; the mainly improvement type is slightly improved about $29.08 \%$, mainly degradation type is very slightly degraded about $7.22 \%$.

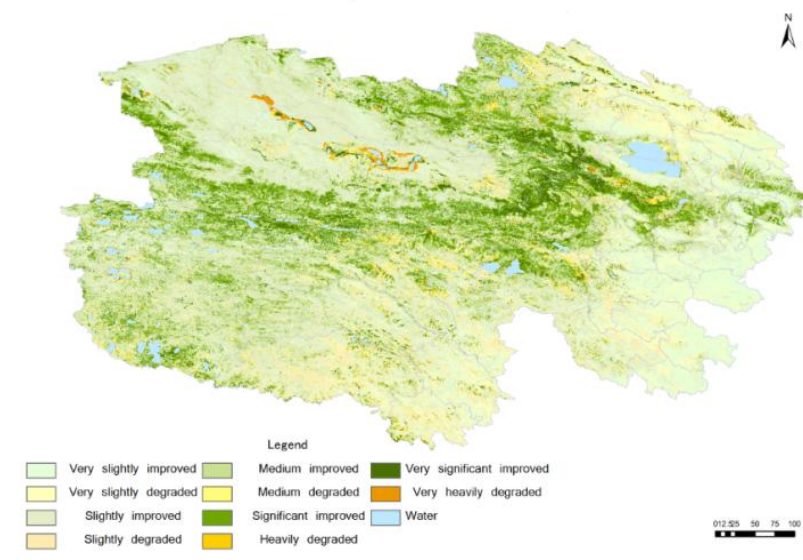

Figure 8 . The vegetation coverage change trend during the period from 2000 to 2012 in Qinghai province

\begin{tabular}{|c|c|c|}
\hline Change Type & area/km2 & Percent $/ \%$ \\
\hline Very slightly improved & 105414 & 15.33 \\
\hline Very slightly degraded & 155086 & 7.22 \\
\hline Slightly improved & 355031 & 29.08 \\
\hline Slightly degraded & 398173 & 6.27 \\
\hline Medium improved & 543216 & 21.09 \\
\hline Medium degraded & 563799 & 2.99 \\
\hline Significant improved & 651735 & 12.79 \\
\hline Heavily degraded & 660183 & 1.23 \\
\hline Very significant improved & 683492 & 3.39 \\
\hline Very heavily degraded & 687667 & 0.61 \\
\hline
\end{tabular}

Table 3. The change trend statistics of vegetation coverage during the period from 2000 to 2012 in Qinghai province

\section{CONCLUSIONS}

In our study, we choose Qinghai province as the study area, combined with field survey data, MODIS-NDVI, MODIS-LAI and other data as the primary data source, integrated use remote sensing technology, spatial analysis and statistical analysis methods to establish a data sets of vegetation coverage in Qinghai Province in 2000 to 2012, and use this data sets to analyze the changes of vegetation coverage in past 13 years, through our research, the main conclusions are following: First, we use field survey data validation the result of vegetation coverage which is estimated by two sub-pixel model method, from the results we can see, utilizing the cumulative NDVI frequency of $0.2 \%$ and $99.8 \%$ of the corresponding value as a parameter value to estimate vegetation coverage across the whole Qinghai province using MODIS data have a higher precision, compare with the values of the reference point we can get the accuracy of estimation is above $80 \%$.

Second, spatial distribution of vegetation coverage in Qinghai province from south to north, east to west has a certain transition characteristics. Over the past 13 years, the area of the steady state region accounted for $57.9 \%$ (including very slightly, slightly improved and degraded), the area of dramatic changes are mainly concentrated in the central and north-central regions, the analysis found that the vegetation coverage have significantly increased trend in most regions of these areas.

Third, through this study, we can quickly and accurately obtain Qinghai vegetation coverage and it can visually reflect change status in vegetation, in order to provide the basis for vegetation resource monitoring in Qinghai Province and provide a 
reference for the ecological environment construction and other related policies, researches and applications.

\section{REFERENCES}

[1] Purevdorj T, Tateishi R, Ishiyama T, 1998. Relationship between Percent Vegetation Cover and Vegetation Indices. International Journal of Remote Sensing, 19, pp. 3519-3535.

[2] Gitelson A A, Kaufman Y J, St ark R, 2002. Novel Algorithms for Remote Estimation of Vegetation Fraction. Remote Sensing of Environment, 80, pp. 76-87.

[3] Chen Yunhao, Li Xiaobing, Shi Peijun, 2001. Estimating Vegetation Coverage Change Using Remote Sensing Data in Haidian District, Beijing. Journal of Plant Ecology, 25(5), pp. 588-593.

[4] Zhang Wenbo, Fu Suhua, Liu Baoyuan, 2001. Error Assessment of Visual Estimation Plant Coverage. Journal of Beijing Normal University( Natural Science), 37(3), pp. 402408.

[5] Frenette M, Julien P Y, 1987. Computer Modeling of Soil Erosion and Sediment Yield from Large Watersheds. International Journal of Sediment Research, 2, pp. 39-68.

[6] Zhou Q, Robson M, Pilesjo P, 1998. On the Ground Estimation of Vegetation Cover in Australian Rangelands. International Journal of Remote Sensing, 9, pp. 1815-1820.

[7] Stow DA, Hope A, McGuire D, 2004. Remote Sensing of Vegetation and Landcover Change in Arctic Tundra Ecosystems. Remote Sensing of Environment, 89(3), pp. 281308.

[8] Jnsson P, Eklundh L, 2004. Program for Analyzing Time $\square$ series of Satellite Sensor Data. Computers and Geosciences, 30(8), pp. 833-845.

[9] CHEN Jin, CHEN Yun_hao, HE Chun_yang, SHI Pei_jun, 2001. Sub_pixel Model for Vegetation Fraction Estimation based on Land Cover Classification. Journal of Remote Sensing, 5(6), pp. 416-422.

[10] Wu Changguang, Zhou Zhixiang, Xiao Wenfa, 2012. Dynamic Monitoring of Vegetation Coverage in Three Gorges Reservoir Area Based on MODIS NDVI. Scientia Silvae Sinicae, 48(1), pp. 22-28.

[11] Niu Baoru, Liu Junrong, Wang Zhengwei, 2005. Remote Sensing Information Extraction Based on Vegetation Fraction in Drought and Half-Drought Area. Geomatics and Information Science of Wuhan University, 1, pp. 27-30.

[12] Ge Liangpeng, Yi Linke, Wang Leitao, 2004. Study on Dynamic Change of Yuli Oasis Plant Cover Based on RDVI. Journal of Arid Land Resources and Environment, 18(6), pp. 66-71.

[13] Gutman G, Ignatov A, 1998. The derivation of the green vegetation fraction from NOAA/AVHRR data for use in numerical weather prediction models. International Journal of Remote Sensing, 19(8), pp. 1533-1543.

[14] Baret F, Guyot G, 1991. Potentials and limits of vegetation indices for LAI and Apar assessment. Remote sensing of environment, 35(2), pp. 161-173.

[15] Choudhury B J, Nizam U A, Sherwood B I, 1994. Relations between evaporation coefficients and vegetation indices studied by model simulations. Remote sensing of environment, 50, pp. 1-17.

[16] Tucker C J, Slayback D A, Pinzon J E, 2001. Higher northern latitude normalized difference vegetation index and growing season trends from 1982 to 1999. International Journal of Biometeorology, 45(4), pp. 184-190.

[17] Wang Huaru, Wang Tianming, Ge jianping, 2012. Variation trends of the vegetations in distribution region of
Amur tiger based on MODIS NDVI. Chinese Journal of Applied Ecology, 23(10), pp. 2821-2828.

\section{ACKNOWLEDGEMENTS}

This research is supported by the basic scientific research fund of Chinese Academy of Surveying and Mapping (No. 7771301). And this work was carried out under China's National Science and Technology Support Program funded by the Ministry of Science and Technology (approved No. 2012BAB16B01). 